\title{
Imagens, práticas e estratégias na implantação da ginecologia em Belo Horizonte: as complexidades de um processo
}

\author{
Images, practices and strategies for the \\ implantation of gynecology in Belo Horizonte: the \\ complexities of a process
}

\author{
Rachel Soihet \\ Professora do Programa de Pós-graduação em História \\ da Universidade Federal Fluminense e pesquisadora do CNPq \\ Rua Cel Moreira César, 300 apt $^{\mathbf{0}} 502$ \\ 24230-063 Rio de Janeiro - RJ - Brasil
}

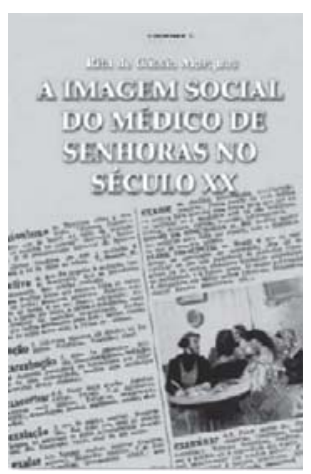

Marques, Rita de Cássia.

A imagem social do médico de senhoras no século XX. Belo Horizonte: Ed. Médica, 2005. 179p.
$\mathrm{O}$ processo de implantação da ginecologia em Belo Horizonte (MG), a partir da análise da trajetória do doutor Hugo Furquim Werneck, e os desdobramentos ocorridos quando de sua substituição na cátedra por ele inaugurada na Faculdade de Medicina, constituem o foco dessa obra. Porém tal propósito se amplia, uma vez que o trabalho fornece ao leitor um panorama da situação da medicina naquela cidade, desde seus primórdios. Embora pretendesse ser moderna, a medicina revelava-se deficiente no que tange ao atendimento médico, cujos profissionais, por sua escassez e fragilidade, compartilhavam a clientela com 'curadores' diversos. E ali, em meio às condições precárias de higiene e às vicissitudes atravessadas pela população pobre, decidemse as elites pela criação de um hospital que se tornaria a Santa Casa de Misericórdia, empreendimento no qual a atuação de Werneck revelouse fundamental. Mas não apenas as lides médicas são abordadas nesse trabalho; ele serve, igualmente, para o descortino de crenças, comportamentos, valores de mulheres e homens de diferentes segmentos sociais, além das injunções políticas que ali se apresentaram nas diversas conjunturas.

Rita Marques demonstra que o processo de medicalização não teria ocorrido de forma avassaladora como apontou uma historiografia inspirada em Foucault, pressuposto, aliás, já contestado por abordagens em outras localidades do país. Desconfiada, igualmente, da sua concretização em Belo Horizonte, Marques, partindo de indícios à moda de Ginzburg, lançando mão de pistas aqui e ali, em um verdadeiro trabalho de bricolagem, buscou reconstruir as relações médico/paciente chegando a uma realidade diversa. Concluiu que o referido processo deu-se muito lentamente e que as citadas relações estruturaram-se a partir de múltiplas estratégias e táticas desenvolvidas pelos médicos para ganharem a confiança das mulheres e, especialmente, de seus pais e maridos. Os médicos, além de competência técnica, deveriam apresentar inúmeros outros atributos, como moral ilibada, acrescida de qualidades humanitárias evidenciadas em práticas como caridade e dedicação, configurando-se como homens 'piedosos', sinônimo de bons católicos. 
Uma tese complementar que igualmente se esfacela com a investigação levada a efeito pela autora é aquela de que o sucesso da medicalização se concretizou com a aliança entre o médico e a mãe, proveitosa para ambos. Com a ajuda da mãe, o médico derrotaria a hegemonia da medicina popular e de suas comadres; em compensação, ampliar-se-ia o poder das mulheres na esfera doméstica, ao ressaltarse a importância da função materna, resultando no declínio do poder do pai naquela esfera. Na realidade, conforme observa Rita Marques, ocorreu o oposto: a medicalização tendeu a retirar o poder das mulheres sobre os cuidados com a sua saúde, passando os homens a interferir nesse assunto, eles que, anteriormente, ficavam à margem da questão. Agora acompanhavam as mulheres ao consultório, pois era impensável uma mulher freqüentar sozinha o ginecologista. Como fora dos grandes centros o médico raramente estava presente, a comunicação com ele se fazia através de cartas dos pais ou maridos, conforme documentação encontrada pela autora nos arquivos de Hugo Werneck. Tal prática não se limitava à burguesia e aos segmentos médios, também entre os populares a intermediação se fazia pelo homem, de acordo com processos judiciais consultados.

Em seu empenho de desconstrução das teses vigentes na década de 1970, a autora retrocede ao período colonial, em que as 'artes de curar' incluíam a invocação aos santos, especialmente por ocasião do parto, quando todos os socorros eram pedidos. Naquele momento, práticas mágicas e religiosas não necessariamente católicas eram realizadas, constatando-se a presença de culturas diversas, resultantes das contribuições de vários grupos - brancos, negros, indígenas. Não podemos esquecer que, no período colonial, os médicos eram raros e muitas vezes considerados 'desnecessários', não se revestindo da aura de poder que os caracterizaria posteriormente. Além do que, como afirma Rita Marques, "as curas aconteciam independentemente da medicina". Assim, os médicos tinham de partilhar seu espaço com outros personagens envolvidos no atendimento à saúde das mulheres: padres, 'rezadores', curandeiros, parteiras e curiosas. O recurso aos manuais de medicina popular, entre os quais se destaca o do médico polonês Chernoviz, constituiu um dos estratagemas para preencher a ausência daqueles especialistas, ao mesmo tempo que retardou o empenho das famílias em contar com a sua presença física, só o chamando quando a situação configurava-se extremamente grave.

Com relação à ginecologia as dificuldades eram maiores, pois o ato de tocar as 'intimidades' das mulheres estava limitado não apenas por proibições religiosas, como também pelo pudor e pela moral vigentes. Lembremo-nos de que, no século XIX, o projeto da burguesia com relação às meninas consistia em desenvolver uma educação moral e repressiva, tendo em vista suas obrigações futuras: obedecer ao marido, serlhe fiel, cuidar dos filhos. Tal projeto, entretanto, não impedia a presença das resistências 'garimpadas' por Rita Marques, evidenciando que nem todas se adequaram passivamente ao modelo que se lhes pretendia impor. O exemplo emblemático dessas resistências é apresentado no relato do caso de Helena Morley, que viveu no interior de Minas Gerais em fins do século XIX. 
Mas a concepção hegemônica era a que determinavam as escrituras, ou seja, de que "bom seria que os homens não tocassem em mulher". Disso decorreu o emprego de vários artifícios, como a utilização de 'manequins' ou 'bonecas' em que as mulheres apontavam o local da dor ou do desconforto, a fim de evitar as 'apalpações desnecessárias', como confessa um dos médicos entrevistados, referindo-se às suas experiências em Belo Horizonte nos primeiros anos do século XX. Tal estado de coisas entrava em contradição com a tendência da medicina, que se centrava cada vez mais no exame do corpo para detectar a origem das doenças e que, em fins do século XIX, já definira as regras para um bom exame ginecológico, o que significava tocar com profundidade o corpo das mulheres. Também cabe não esquecer o constrangimento das mulheres em conversar com um homem estranho - o médico sobre questões ligadas à sexualidade, o que tornava o sigilo um aspecto fundamental para esses profissionais, a fim de ganhar a confiança de suas clientes.

Nesse contexto, Hugo Werneck, que provinha do Rio de Janeiro, onde seu pai já se destacava na prática ginecológica, foi convidado em 1908 para o cargo de diretor clínico da Santa Casa. Recém-chegado da Europa, de onde trazia novos conceitos e técnicas para o atendimento às mulheres, Werneck é considerado o introdutor da ginecologia em Belo Horizonte. Até então os médicos que atendiam aos partos e aos males da área genital feminina se apresentavam como 'médicos de senhoras', atuando igualmente em outras especialidades, diante da preferência dada às parteiras. Também o doutor Werneck, embora se nomeasse ginecólogo, não escapou a esse destino, dedicando-se da mesma forma ao tratamento de ambos os sexos e destacando-se por suas qualidades de cirurgião e generalista.

Mostra-nos Rita Marques como cresceu o prestígio de Hugo Werneck por sua atividade na Santa Casa de Misericórdia, na qual se destacou como hábil administrador, responsável pela modernização da instituição. Cumpria à risca os novos padrões de higiene, consciente da importância destes para a expansão dos horizontes da medicina e, principalmente, da cirurgia. Paralelamente, trouxe irmãs de caridade alemãs para ali atuarem, a fim de garantir respeitabilidade e eficiência aos serviços prestados, assim como um bom relacionamento com a Igreja. Igualmente buscou prover o hospital com os mais atualizados equipamentos, com o objetivo de atrair setores da elite na categoria de pensionistas. Promoveu, ainda, a abertura (1911) de uma enfermaria de mulheres na Maternidade, para a qual atraiu o trabalho voluntário de mulheres das camadas burguesas. Também em 1911 inaugurou-se a Faculdade de Medicina de Belo Horizonte, passando a Santa Casa a funcionar como campo para as práticas dos acadêmicos, o que a obrigou a oferecer todas as especialidades contempladas no curso, inclusive aquela de ginecologia e obstetrícia, ministrada por Werneck.

Não foram poucos os obstáculos enfrentados para quebrar a resistência da população quanto ao hospital, então considerado um lugar para os que iam morrer. E o projeto do doutor Werneck era atrair para a maternidade não apenas as mulheres pobres, mas também aquelas de segmentos mais elevados, o que se revelou ainda mais complicado. 
Isto porque a Santa Casa não apenas era associada aos pobres, como também era vista como um lugar onde mães solteiras e prostitutas tinham seus filhos, um espaço bem distinto daquele da tradição domiciliar do atendimento pelas parteiras.

Aliada a essa tradição, a precariedade no atendimento à saúde deu lugar a uma maior tolerância dos médicos em relação às parteiras, que permaneceram exercendo funções mesmo nos hospitais especializados - as maternidades. Assim, em que pesem alguns discursos furiosos de médicos contra as parteiras, vistas em sua maioria como "mulheres sem qualquer instrução real", a preferência popular que sobre elas incidia implicou uma solução de meio-termo, em que os médicos, muitas vezes com recursos públicos, patrocinavam 'cursos de parteiras'. Dessa forma, demonstra Rita Marques que a eliminação das parteiras no atendimento aos partos ocorreu muito lentamente e que elas permaneceram prestigiadas e exercendo funções nas maternidades ainda nos anos 40.

Além disso, predominavam em Belo Horizonte as parteiras práticas, apesar dos esforços do doutor Werneck para a introdução de parteiras diplomadas e obstetrizes. As mulheres da elite, apesar de exercerem filantropia em favor da maternidade, eram avessas a terem ali seus filhos. Somente à medida que se firmou a autoridade dos médicos, acompanhada pela consolidação dos laços de confiança entre os médicos e as mulheres, ocorreu - como demonstra a autora - uma transformação nesse panorama. Assim, paulatinamente, foram os médicos apropriando-se do espaço das parteiras, tendo como principal arma a difusão da importância da higiene nos padrões hospitalares como a única adequada ao atendimento das parturientes. Fato que não exclui a existência de relatos de parteiras atendendo no Hospital das Clínicas em Belo Horizonte na década de 1970.

Porém, na construção da relação médico/paciente, no tocante à ginecologia, não bastavam os progressos da medicina; era igualmente importante conseguir a confiança das mulheres e de seus pais ou maridos. E, para isso, a imagem de 'bom católico' revelava-se fundamental, transferindo-se a imagem do santo e do padre para o médico. Nesse sentido, a expressão 'bom médico' significava ser caridoso e confiável. O médico jovem, recém-formado e solteiro, poucas chances teria de estabelecer uma boa clientela. Mostrar-se caridoso, trabalhando gratuitamente, era uma boa forma de se fazer conhecido e conseguir uma boa clientela, no que o trabalho voluntário na Santa Casa de Misericórdia revelava-se fundamental. Além disso, o anúncio em jornais, principalmente católicos, contribuía para divulgar não apenas os serviços como também a qualificação profissional do médico - por exemplo, a realização de estágio na Europa, como fez o próprio Werneck.

Ser piedoso e ver a medicina como um sacerdócio teria, na concepção da autora, papel fundamental no momento de institucionalização da medicina em Belo Horizonte. Para tal asserção, Rita considera as dificuldades do poder público em se responsabilizar totalmente pela assistência aos necessitados. Nesse sentido, a autora apresenta-nos variada correspondência dirigida a Hugo Werneck, onde lhe solicitavam inúmeros favores, especialmente o atendimento gratuito, ou agradeciam os serviços prestados, observando-se aí o enaltecimento de 
suas qualidades beneméritas. Entretanto, essa imagem santificada não era unânime, ao menos no que dizia respeito aos seus alunos, e também aqui a autora esmerou-se na coleta de testemunhos. "A mocidade não o amava", assim começa um deles, embora reconhecendo sua "participação sincera de ensinar". Um outro testemunho, nada menos que o do memorialista Pedro Nava, aluno de Werneck, enumera "traços de sua personalidade como sua teimosia, impulsividade, facilidade de se encolerizar, e sua agressividade", quando seus auxiliares "viam o diabo nas suas mãos ... Além disso, ele era de uma variabilidade de humor levada ao extremo". Para as clientes, porém, sua imagem mantinha-se intacta, conforme depoimento de uma delas que se confessava "reconhecida e grata", caracterizando-o como um "benfeitor a mãos cheias e sem olhar a quem".

Diante do crescimento do protestantismo e do ceticismo, a Igreja iniciou um projeto de 'recatolização' da elite, liderado por D. Sebastião Leme, e para tal buscou a adesão de intelectuais, entre os quais os médicos católicos que formaram associações. Em Belo Horizonte, na década de 1930 é criada a Corporação de Médicos Católicos, de cuja cerimônia de fundação participou Hugo Werneck. Espaço de discussão de assuntos variados, ali os temas médicos eram sempre entremeados pela religião, sendo seus membros muito atuantes, manifestando-se em vários meios de comunicação. Nos novos tempos, não mais bastava freqüentar missas e mostrar-se piedoso para ser reconhecido como bom médico; era preciso assumir uma postura militante. Até porque o crescimento dos médicos católicos foi paralelo ao de outros grupos, dando lugar a choques entre seus seguidores numa disputa de espaço nas instituições médicas e na sociedade. Tais transformações contribuíram para que um dos embates mais acirrados entre os médicos católicos e os 'ateus' ocorresse quando da disputa para substituição do catedrático de Ginecologia, após o falecimento de Hugo Werneck, em 1935.

As mudanças que se operaram em Belo Horizonte e no país deram margem para que ocupasse a referida cátedra o Dr. Clóvis Salgado, que não se adequava ao modelo de médico 'piedoso'. Esse fato provocou uma ruptura com a Igreja, que o impediu de ministrar aulas práticas na Santa Casa, levando-o a inaugurar o Hospital de Ginecologia em 1937. Isso não o dispensou, entretanto, de recorrer ao trabalho de irmãs de caridade, e de buscar cultivar a imagem de homem generoso e caridoso.

O trabalho de Rita Marques destaca-se como uma original e importante contribuição para o estudo da história da medicina no Brasil, bem como se revela repleto de subsídios especialmente para a compreensão de uma especialidade médica - a ginecologia - em Belo Horizonte nas primeiras décadas do século XX. Através desse estudo são desvendadas as resistências engendradas pelas mulheres, assim como pelos seus pais e maridos, num processo em que os médicos tiveram de lançar mão de estratégias e táticas que só lentamente lhes garantiram reconhecimento e autoridade, ao contrário do que afirmaram os primeiros escritos sobre a matéria. E muito mais é encontrado na obra, mas urge possibilitar aos leitores e leitoras o prazer de desvendar esse trabalho. 